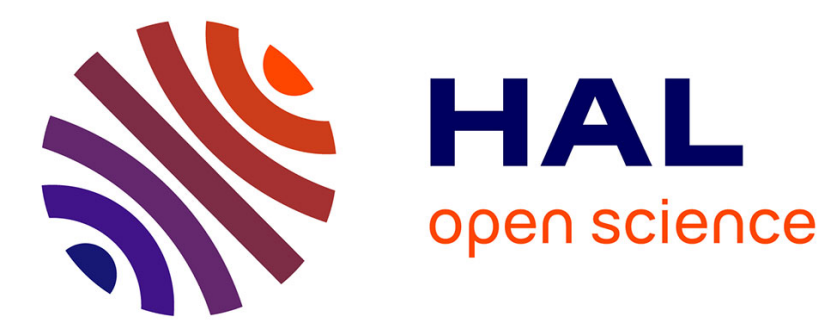

\title{
Transition from copper to fiber broadband: the role of connection speed and switching costs
}

\author{
Lukasz Grzybowski, Maude Hasbi, Julienne Liang
}

\section{To cite this version:}

Lukasz Grzybowski, Maude Hasbi, Julienne Liang. Transition from copper to fiber broadband: the role of connection speed and switching costs. Information Economics and Policy, 2018, 42, pp.1-10. 10.1016/j.infoecopol.2017.07.001 . hal-02102338v2

\section{HAL Id: hal-02102338 \\ https://hal.science/hal-02102338v2}

Submitted on 8 Nov 2019

HAL is a multi-disciplinary open access archive for the deposit and dissemination of scientific research documents, whether they are published or not. The documents may come from teaching and research institutions in France or abroad, or from public or private research centers.
L'archive ouverte pluridisciplinaire HAL, est destinée au dépôt et à la diffusion de documents scientifiques de niveau recherche, publiés ou non, émanant des établissements d'enseignement et de recherche français ou étrangers, des laboratoires publics ou privés. 


\title{
Transition from copper to fiber broadband: the role of connection speed and switching costs
}

\author{
Lukasz Grzybowski* $\quad$ Maude Hasbi ${ }^{\dagger} \quad$ Julienne Liang ${ }^{\ddagger}$
}

December 6, 2016

\begin{abstract}
We estimate a mixed logit model using data on choices of broadband technologies by 94,388 subscribers to a single broadband operator in a European country on a monthly basis from January to December 2014. We find that valuation of DSL connection speed in the range between 1 and $8 \mathrm{MB} / \mathrm{s}$ is very similar. Moreover, in January 2014, the valuation of FttH connection with speed of $100 \mathrm{MB} / \mathrm{s}$ is not much different than of DSL connection with speed of 1 or $8 \mathrm{MB} / \mathrm{s}$ but it increased over time. The small initial difference in valuation of DSL and FttH connections may be because basic Internet needs of consumers such as emailing, reading news, shopping, browsing and even watching videos online could be satisfied with connection speed below $8 \mathrm{MB} / \mathrm{s}$. We also find that consumers face significant switching costs when changing broadband tariffs, which are substantially higher when switching from DSL to FttH technology. According to counterfactual simulations based on our model estimates, switching costs between technologies are the main factor which slows down transition from DSL to FttH.
\end{abstract}

Key Words: FttH, DSL, connection speed, switching costs

JEL Classification: L43,L50, L96

\footnotetext{
${ }^{*}$ Corresponding author: Telecom ParisTech, Department of Economics and Social Sciences, 46 rue Barrault, 75013 Paris, France. E-mail: lukasz@mushroomski.com

${ }^{\dagger}$ Telecom ParisTech, Department of Economics and Social Sciences, 46 rue Barrault, 75013 Paris, France. E-mail: maude.hasbi@telecom-paristech.fr

${ }^{\ddagger}$ Orange, 78 rue Olivier de Serres, 75505 Paris, France. E-mail: julienne.liang@orange.com
} 


\section{Introduction}

In the last years, the European Commission has been pursuing the objective of providing fixed broadband Internet access to all households in the European Union. But apart from universal broadband availability, the Commission also increasingly cares about the quality of access in terms of broadband speed. According to the Digital Agenda for Europe, by 2020, all EU households should benefit of at least $30 \mathrm{MB} / \mathrm{s}$ connection and at least $50 \%$ of EU households should have adopted $100 \mathrm{MB} / \mathrm{s}$ connection or more. ${ }^{1}$ In September 2016, the Commission further announced that by 2025 all European households should have access to connections with speed of at least $100 \mathrm{MB} / \mathrm{s}$. To achieve this objective, the Commission proposed "a new European Electronic Communications Code including forward-looking and simplified rules that make it more attractive for all companies to invest in new top-quality infrastructures, everywhere in the EU, both locally and across national borders." According to the Commission, these investments could "boost the GDP of the EU by an additional 910 billion Euros and create 1.3 million new jobs by 2025". ${ }^{2}$ Furthermore, the roll-out of high speed broadband access should enable the development of new and enhanced digital services, thus raising consumer welfare and increasing the competitiveness and reach of EU businesses.

Broadband services were originally provided using Digital Subscriber Line (DSL) technology which relies on copper networks and offers speed up to $8 \mathrm{MB} / \mathrm{s}$ and cable modem. ${ }^{3}$ From 2010 onwards, telecommunications incumbent operators and new entrants in Europe started to invest in fiber optic networks, which are rolled out up to the customer's premises (Fiber to the Home or FttH) and can carry video, data, voice and interactive video-telephone services. FttH connections should offer speeds of $100 \mathrm{MB} / \mathrm{s}$ and more, which match the objectives set out by the Commission. However, as of June 2015, about $70 \%$ of of EU households with fixed

\footnotetext{
1 "A Digital Agenda for Europe," European Commission, COM(2010) 245.

${ }^{2}$ Source: "State of the Union 2016: Towards a Better Europe - A Europe that Protects, Empowers and Defends"

${ }^{3}$ The highest speed of DSL connection is $8 \mathrm{MB} / \mathrm{s}$. ADSL2+ and VDSL provide higher speed in the range between $8 \mathrm{MB} / \mathrm{s}$ and $50 \mathrm{MB} / \mathrm{s}$ for premises which are located close to the exchange. Thus, these advanced technologies are not available to all consumers.
} 
broadband connection used DSL connections. ${ }^{4}$ The main reason for such high share of slower DSL connections is that alternative high speed technologies such as FttH and cable modem are still not available to the majority of EU households. In countries where cable coverage is similar to DSL both technologies have comparable market shares. ${ }^{5}$

Since the liberalization of fixed-line telecommunications markets in 1998, the policy and academic debates focused on how to regulate access to fixed broadband infrastructure owned by the previous monopolists and incentivize firms to invest in high speed broadband networks. But the relatively small share of high speed broadband technologies may be influenced by needs and preferences of consumers with respect to Internet access and by difficulties to switch to other broadband technologies. First, DSL users may not be aware at all which broadband technology they currently use to access Internet and how quality of connection would change if they switched from DSL to FttH or cable modem. With this respect broadband technologies may resemble experience goods. Second, there may be substantial switching costs between technologies due to transaction costs, opportunity cost of time and other, which may hold back consumers from changing tariffs, operators and adopting higher-speed technology. Third, the price difference between DSL and FttH services may be too high compared to the benefits perceived by consumers to justify switching. Finally, the presence of indirect network externalities may also slow down fiber adoption. On the one hand, consumers will switch from copper to fiber technology if they can access new online content and services. On the other hand, new online content and services will be developed only if there are sufficiently many consumers with high speed broadband connections. ${ }^{6}$ For these reasons, it may be a challenge to achieve the objectives set out by the Commission on broadband access on time. According to the EU Digital Single Market

\footnotetext{
${ }^{4}$ Source: European Commission 2015 Digital Scoreboard.

${ }^{5}$ As of December 2014, only $6 \%$ of households in the EU had access to fiber, $19 \%$ to cable broadband and $4 \%$ to other fixed broadband technologies. At the same time, about $59 \%$ of households had access to DSL, with large differences across Member States determined by the development of fixed-line infrastructure. Historically, Eastern European countries had poorer fixed-line infrastructure and in result have lower DSL coverage nowadays, as compared to almost full coverage in most Western European countries. Source: 2015 EU Digital Single Market Report

${ }^{6}$ Baranes (2014) analyzes theoretically interplay between network investment and content quality on the Internet.
} 
Report, in December 2014, only $26 \%$ of fixed broadband subscriptions in the EU had speeds over $30 \mathrm{MB} / \mathrm{s}$ and $9 \%$ over $100 \mathrm{MB} / \mathrm{s}$.

In this paper, we analyze the role of connection speed and switching costs between tariffs and technologies in the transition from DSL to FttH. More specifically, we focus on the consumers' choices of broadband tariffs based on DSL and FttH networks when both technologies are available at consumer's premises. We use information on broadband technologies used by 94,388 subscribers to a single broadband operator in a European country on a monthly basis from January to December 2014. We estimate a mixed logit model of demand for broadband tariffs in dependence on tariff characteristics including price and speed of DSL connections, which is calculated using information on copper line loss. In addition, we consider that consumers may face frictions when changing tariffs and technologies due to switching costs which may therefore slow down transition from copper to fiber technology. We use the estimated model to conduct counterfactual simulations, which illustrate the relative importance of broadband speed and switching costs for consumer choices of DSL and FttH connections.

We find that consumers face significant switching costs when changing broadband tariffs and technologies. Switching costs are substantially higher when consumers switch from DSL to FttH tariffs, which may be due to additional costs needed to set up the first FttH connection. In particular, a consumer needs to make an appointment with an engineer who must visit the premises to set up a connection. Our counterfactual simulation shows that adoption of FttH, which stands at $29 \%$, would be higher by about 25 percentage points in the last period in the data in the absence of additional switching costs from DSL to FttH technology. In the absence of switching costs between tariffs the share of FttH connection would not change at all, while in the absence of both tariff and technology switching costs it would be higher by about 62 percentage points reaching adoption share of $91 \%$.

Furthermore, we find that the valuation of speed in the range of 1 to $8 \mathrm{MB} / \mathrm{s}$ is very similar, which may be because basic Internet needs of consumers such as emailing, reading news, shopping, browsing and even watching videos online can be satisfied with connection speed within this range. Surprisingly, the initial valuation of FttH speed of $100 \mathrm{MB} / \mathrm{s}$ was not much different from $8 \mathrm{MB} / \mathrm{s}$ but increased over time. In January 2014, the first month of our data, the valuation 
of $\mathrm{FttH}$ connection with speed of $100 \mathrm{MB} / \mathrm{s}$ was higher by only $3 \%$ than the valuation of DSL connection with speed of $8 \mathrm{MB} / \mathrm{s}$ and was higher by $7 \%$ than the valuation of DSL connection with speed of $1 \mathrm{MB} / \mathrm{s}$. In December 2014, the last month of our data, the valuation of $\mathrm{FttH}$ connection with speed of $100 \mathrm{MB} / \mathrm{s}$ was higher by $59 \%$ than of DSL connection with speed of 8 $\mathrm{MB} / \mathrm{s}$ and was higher by $66 \%$ than of DSL connection with speed of $1 \mathrm{MB} / \mathrm{s}$. Increasing valuation over time reflects growing need for high speed connections, which may be due to availability of new online services and marketing of FttH connections. However, besides fast changes over time, the ratio of speed valuations in the last month of the data remains far below the ratio of speed values.

We use the model to conduct a number of counterfactual simulations. Assuming that speed of $\mathrm{FttH}$ connections is $100 \mathrm{MB} / \mathrm{s}$, in the presence of switching costs, the take-up of FttH would not change at all if speed of all DSL connections varied between $1 \mathrm{MB} / \mathrm{s}$ and $50 \mathrm{MB} / \mathrm{s}$. Also, in the absence of switching costs, the take up of FttH would remain almost unchanged if speed of all DSL connections varied between $1 \mathrm{MB} / \mathrm{s}$ and $8 \mathrm{MB} / \mathrm{s}$, compared to the benchmark case without switching costs. Moreover, relative to the benchmark case, the share of FttH connections would be lower only by 14 percentage points, if speed of all DSL connections increased to $50 \mathrm{MB} / \mathrm{s}$. These counterfactual simulations suggest that switching costs between tariffs and technologies are the main factor which slows down transition from DSL to FttH.

Due to lack of detailed consumer-level information on technology choices over time, the literature on adoption of broadband technologies relied mainly on aggregate country-level data. For instance, Distaso et al. (2006) and Bouckaert et al. (2010) use data on EU and OECD countries respectively to analyze the role of inter- and intra-platform competition for broadband diffusion. ${ }^{7}$ Dauvin and Grzybowski (2014) study the same question using more detailed NUTS 1 regional data for the EU countries. Among few studies which focus on fiber adoption, Wallsten and Hausladen (2009) use data for 27 EU countries in years 2002-2007 and conclude that the adoption of Fttx technology is lower in countries in which local loop unbundling (LLU) is more

\footnotetext{
${ }^{7}$ Inter-platform competition happens when entrants build their own infrastructure, while intra-platform competition happens when entrants lease access to incumbents' facilities via local loop unbundling.
} 
effective. $^{8}$ More recently, Briglauer (2014) uses data for 27 EU countries in years 2004-2013 and finds that more effective regulatory-induced service-based competition has a negative impact on Fttx subscriptions.

There is also a growing body of literature studying substitution between broadband technologies based on individual-level data. For instance, Cardona et al. (2009) use survey data of households in Austria to estimate discrete choice models for Internet access through DSL, cable and mobile broadband and conclude that there is substitution between fixed and mobile broadband. Grzybowski et al. (2015) estimate a mixed logit model for households' choices of broadband technologies in Slovakia and use the estimates of price elasticities to conclude that mobile broadband should be included in market definition for DSL. In another paper, Srinuan et al. (2012) use discrete choice model and survey data for Sweden and find that mobile broadband and fixed broadband technologies are close substitutes when they are locally available. There are also a few studies which analyze the migration from old to new technologies. For instance, Ida and Kuroda (2006) use survey data and estimate discrete choice model to analyze migration from narrowband to broadband in Japan. In another paper also for Japan, Ida and Sakahira (2008) analyze migration from DSL to FttH technology. They identify income, service usage such as motion-picture viewing, and type of residence as primary determinants of FttH subscriptions. They also conclude that there is a significant lock-in effect in technology adoption but they study inter-temporal choice dependence using survey data from a single time period.

In this paper, we analyze the role of switching costs in the adoption of broadband technologies following the approach in Grzybowski and Liang (2015). They estimate a mixed logit model using data on subscribers to mobile services from a single European operator and find that there are substantial switching costs between tariffs which reduce consumer surplus. In this paper instead, we use a sample of subscribers to fixed broadband services. Some of them use quadruple play tariffs which bundle fixed and mobile services. Our paper is also related to studies which analyze the role of speed of broadband connections. For instance, Rosston, Savage and Waldman (2010) use discrete choice experiments to estimate the marginal willingness to pay for

\footnotetext{
${ }^{8}$ Local loop unbundling is the regulatory process of allowing multiple telecommunications operators to use connections from the telephone exchange to the customer's premises.
} 
improvement in broadband services in the US in 2003 and 2010. They show that customers' willingness to pay for speed is rather low and increases with education, income and on-line experience. A US household is willing to pay $3 \$$ more in order to enjoy ultra-fast broadband rather than basic broadband. In another paper, LaRose et al. (2014) find a positive effect of experience on speed valuation, which confirms that broadband technology resembles experience good.

The remainder of the article is organised as follows. Section 2 presents the data used in the estimation. Section 3 introduces the empirical model. Section 4 presents the main results. Section 4.1 presents the counter-factual simulations results. Finally, Section 5 concludes.

\section{The Data}

In this analysis we use two unique data sets, which were made available to us by a European telecommunications provider of both fixed and mobile services. The first database includes information on fixed broadband tariffs used by a few million customers from the whole customer base on monthly basis from January 2014 to December 2014. Next, we kept only consumers with premises connected to fiber network, i.e., consumers who are eligible to have FttH access. We then randomly drew 100,000 consumers. Consumers who left the operator in a given month were replaced by new arrivals in the same number. We lost a number of consumers during data cleaning, mainly those using older broadband and mobile tariffs for which we do not have information. The final sample consists of 94,388 consumers. These customers subscribed to one of the operator's broadband offers: (i) a 'naked' Internet access offer; (ii) 'double play' offer which includes Internet access and fixed telephony over IP (IP Telephony); (iii) ‘triple play' offer which includes Internet access with IP Telephony and television over IP (IPTV); or (iv) 'quadruple play' offer which includes IP Telephony, IPTV and access to mobile services. Moreover, we have information on whether a consumer kept his fixed-line connection for voice calls (PSTN), in which case he pays extra for it. For each consumer we also have information on the postal address which can be linked to one of about 36,000 municipalities in France. Moreover, for each quadruple play consumer we know the remaining commitment period in months. 
For 58,455 customers in this sample we have information on the copper line quality in terms of the copper line loss measured in decibel as of December 2010 and December 2013. ${ }^{9}$ The copper line loss determines the speed of DSL connection which may take approximate values of $1,2,5,7$ and $8 \mathrm{MB} / \mathrm{s}^{10}$ Importantly, the price for DSL access does not depend on speed. Besides, the speed of $\mathrm{FttH}$ connection is approximately $100 \mathrm{MB} / \mathrm{s}$ and is not dependent on the distance from the consumer's house to the exchange.

The second database includes information on: (i) all the new fixed broadband offers based on DSL and FttH technologies which were available in each month during the period of our analysis and (ii) old tariffs which consumers still use but which cannot be selected anymore in the period of our analysis. For each fixed broadband offer, we have information on price and other attributes. In addition, for quadruple play offers the attributes include services which are available on mobile phones. In particular, we have information on voice and data allowance, whether handset subsidy is included in the offer and what is the contractual commitment length. We also know whether the offer can only be purchased on the operator's website. The information on available tariffs is used to create choice set for each consumer.

These two data sets are completed with additional municipality-level information. For each municipality, we know whether there is a cable network available which was upgraded to FttLA (Fiber to the Last Amplifier) that can provide high speed broadband connection of above 30 $\mathrm{MB} / \mathrm{s}$. This information was extracted from the websites of cable operators and is merged with the consumer-level data using unique municipality codes. We also extracted information on the availability of other fiber operators in the municipalities. But since they are available in the same municipalities in which our operator deployed FttH, this information is not useful in the estimation.

\footnotetext{
${ }^{9}$ Broadband signals from the exchange suffer attenuation as they travel along the copper line from the exchange to customer's house, which reduces the speed of DSL access. In general, the longer is the distance from customer's house to the exchange, the higher is the copper line loss. The copper line loss ranges from $1.5 \mathrm{~dB}$ to $75 \mathrm{~dB}$ with a mean value of $27 \mathrm{~dB}$.

${ }^{10}$ In this analysis we ignore the fact that some consumers who live close to the exchange may use ADSL2+ and VDSL connections which provide speed between $8 \mathrm{MB} / \mathrm{s}$ and $50 \mathrm{MB} / \mathrm{s}$.
} 


\section{The Choice Set}

Our modeling approach is closely related to Grzybowski and Liang (2015) who study the role of switching costs in consumer choices of mobile telecommunications services. We borrow from their paper the description of choice set, switching costs and econometric model.

Modeling consumers' decisions by means of discrete choice requires definition of choice set. We construct the choice set for each month in the following way. 'Old' consumers, who were subscribers to broadband services of our operator already in the first month of the data, can decide to: (i) keep their old tariff; (ii) switch to a new tariff from the list of offers available in a given month; (iii) leave their current operator's services. 'New' consumers in the first period do not have in the choice set option (i) to keep the old tariff. Consequently, the choice set is different for most 'old' consumers due to different old tariff, but is the same for all consumers who are 'new' in a given month.

We determine the set of new tariffs in each month using the subscriptions database. We consider a tariff to be new whenever in a given month there was at least one 'new' consumer who selected this tariff or at least one 'old' consumer who switched to it. Otherwise, the tariff is considered as old and not available in a given month. Hence a new tariff in one month becomes an old and unavailable tariff in the next month if there are no 'new' consumers who choose it or 'old' consumers who switch to it. The total number of unique new tariffs in the time period considered is 228 out of which 139 are quadruple play tariffs. The number of available new tariffs ranges between 108 and 139 per month. The remaining tariffs to which consumers subscribe are considered to be old tariffs. There were in total 122 unique 'old' tariffs used by consumers in our sample during 2014.

A consumer's complete choice set in a given month consists of new tariffs in this month and includes the tariff which he used in the previous period. However, since consumers may not be aware of all the tariffs which are on offer, an alternative approach is to limit the choice set

by drawing randomly a number of tariffs from the complete choice set. Due to a large size of our sample and choice set, we estimate a model which consists of 4-5 choice alternatives. 'Old' consumers who do not switch tariff have the following choices: (i) their 'old' tariff; (ii) 'new' 
DSL tariff which is randomly drawn from the list of offers available in a given month; (iii) 'new' FttH tariff which is randomly drawn from the list of offers available in a given month; (iv) outside option to leave the operator. Importantly, the choice set of 'old' consumers who switch tariffs must include the newly selected tariff. ${ }^{11}$ Thus, 'old' consumers who switch have in the choice set as 5th choice alternative, the 'new' tariff to which they switch. 'New' consumers, on the other hand, have in their choice set: (i) selected 'new' tariff; (ii) 'new' DSL tariff which is randomly drawn from the list of offers available in a given month; (iii) 'new' FttH tariff which is randomly drawn from the list of offers available in a given month; (iv) outside option to leave the operator.

In general, consumers who do not opt for fixed-mobile bundles, i.e., quadruple play tariffs, may combine broadband services from our operator with mobile services from our operator or competitors. These services may be either prepaid or post paid. Moreover, consumers who choose option (iv) leaving our provider may also mix and match broadband and mobile services from other operators.

The utility which a consumer derives from these tariffs depends on a set of attributes. The attributes of broadband only tariffs are: (i) the list price per month; (ii) access to the Internet via DSL or FttH technology; (iii) the commitment length; (iv) fixed-line PSTN connection. The attributes of quadruple play tariffs are: (i) the list price per month; (ii) access to the Internet via DSL or FttH technology; (iii) the commitment length; (iv) whether a handset subsidy is offered or a SIM card only without a subsidy; (v) whether voice minutes are unlimited and, if not, what is the volume of minutes included; and (vi) the volume of mobile data in GBs included. In the case of DSL, the additional information is the connection speed, which is determined by the copper line loss of consumer's connection. We construct a set of dummy variables for discrete tariff characteristics and otherwise use continuous variables. Table (1) shows summary statistics for 'new' and 'old' tariffs which are used by consumers in our data.

\footnotetext{
${ }^{11}$ We also estimated a model with choice set including all new tariffs available in a given month which greatly expands the size of data. We were able to estimate multinomial logit model which yields almost identical results, except for the coefficient of switching dummy which is greater in magnitude. However, the size of data does not allow efficient estimation of mixed logit model.
} 


\section{Switching Costs}

Each consumer can: (i) stick to their current tariff and avoid switching costs; (ii) migrate to a new tariff with the same operator bearing some switching costs; (iii)) stop using their tariff and leave for another operator, in which case there are also some switching costs to bear.

Switching costs cause an inertia towards keeping a current plan, even though alternative tariffs may be more attractive in terms of characteristics and prices. When a consumer decides to migrate from their current tariff to a new one, the utility gain must compensate the disutility associated with switching costs, and similarly when a consumer chooses to leave for another operator. To account for this, we define three types of switching costs variables in the following way. First, the switching costs dummy takes value zero when a consumer considers choosing the same tariff as in the previous month and one for all alternative tariffs available in a given month. This switching dummy is interpreted as the disutility from switching to an alternative tariff, to which we refer as switching costs between tariffs. Second, the switching costs dummy for leaving the operator takes value zero for the choice of all tariffs, including the one selected before, and one for the choice of outside option which is leaving the operator. The lack of precise information about what consumers do when they choose the outside option causes a problem with the identification of the costs of switching to the outside option. This is because a dummy variable for switching to the outside option is equivalent to a dummy variable for the valuation of the outside option. Hence, this dummy variable represents a combination of disutility from switching and the utility which a consumer gets from this option. The interpretation of this dummy variable as switching costs is not appropriate and instead we call it leaving dummy. Third, consumers who did not have FttH before may have higher switching costs because a visit from a technician is needed to set up the first fiber connection. There may be also additional costs for FttH users who decide to switch back to DSL. We refer to these additional costs as switching costs between technologies.

In the case of switching to alternative tariffs, since there are no tariff dummy variables used in the estimation, the switching costs dummy may also include the utility from these alternative tariffs. However, if tariff attributes which we use in the estimation fully represent the utility of 
the tariff, the coefficient on the switching dummy can be interpreted as switching costs. The consumer database includes information on tariff used by a consumer in each month. It also includes the length of the remaining commitment period in months in the case of quadruple play tariffs, which may influence the ability of the consumer to switch tariff or to leave the operator. In general, consumers can freely switch tariffs during their commitment period.

Another problem with the identification of switching costs are unobserved time-persistent preferences. Following Heckman (1981), consumer behavior may be state dependent because of true and spurious factors, where true state dependency is a consequence of all observable factors, including switching costs and spurious state dependency results from persistent heterogeneity in preferences for brands. Consumers may continue using the same tariff because it better fits their individual tastes. When spurious state dependency is ignored, the parameters representing switching costs may be overestimated, i.e., state dependency in choices of tariffs appears to be only due to switching costs. We allow for unobserved time-persistent individual preferences by means of mixed logit estimation for panel data. We use two random coefficients in the estimation on price and switching costs.

The total number of tariff switches made by consumers in our sample in 2014 is 46,760 out of 992,550 monthly tariff choice observations, which represents $4.7 \%$. There is some variation in the number of switches per month ranging between $3.3 \%$ and $5.5 \%$. Table 3 shows the number of switchers in the database, which indicates that $60 \%$ never switched a tariff, $32 \%$ switched once, $7 \%$ twice and $1 \%$ three times or more. These numbers suggest that switching tariffs during the period of one year is relatively frequent but less common than in the case of mobile services, as reported in Grzybowski and Liang (2015).

\section{Econometric Model}

We estimate discrete choice model assuming that each individual in a given month chooses tariff

which maximizes his utility from the choice set described above. We use standard linear utility specification which depends on tariff characteristics and observable and unobservable individual characteristics. We account for the heterogeneity in preferences using random coefficients on 
price and switching costs dummy. The utility of individuals $i=1, \ldots, N$ derived from tariff $j=1, \ldots, J$ in month $t$ is given by:

$$
U_{i j t}=x_{j t}^{\prime} \beta-\alpha_{i} p_{j t}+s_{i j k t}^{\prime} \gamma_{i}+\epsilon_{i j t}=V_{i j t}+\epsilon_{i j t}
$$

where the price of tariff is denoted by $p_{j t}$, and $\alpha_{i}$ is the individual-specific valuation of price. Note that all consumers are presented with the same prices of tariffs which are independent of usage. In the case of broadband only tariffs, the vector $x_{j t}^{\prime}$ includes the following variables: (i) a dummy for DSL broadband; (ii) a dummy for FttH broadband; (iii) connection speed; (iv) dummies for 12 and 24 months contracts; (v) a dummy for fixed-line PSTN connection. In the case of quadruple play tariffs, the following variables are included: (i) a dummy for DSL broadband; (ii) a dummy for FttH broadband; (iii) connection speed; (iv) a dummy for handset subsidy; (v) a dummy for web only offer without commitment; (vi) dummies for 12 and 24 months contracts; (vii) a dummy for unlimited voice minutes; (viii) mobile data included in the offer.

The vector of switching dummies is denoted by $s_{i j k t}^{\prime}$ and coefficients $\gamma_{i}$ represent the disutility from switching which approximates switching costs. As discussed in the previous section, we consider two types of switching dummies. The first one takes value zero if consumer $i$ in the previous month $t-1$ used alternative $k=j$ and otherwise value one when $k \neq j$. The second one takes value zero for the choice of any tariff and one for the choice of outside option, which is leaving the operator. This is disutility or benefit from leaving the operator. We also allow for additional switching costs when consumers consider switching to other technology. For users of quadruple play tariffs switching costs are also allowed to vary in dependence on the number of commitment months left. We discussed the identification of switching costs in the previous section.

Finally, $\epsilon_{i j t}$ is the individual-specific valuation for tariff $j$ at time $t$, i.e., the "logit error term". It is assumed to be identically and independently distributed over tariffs and individuals according to type I extreme value distribution. The random coefficients $\left(\alpha_{i}, \gamma_{i}\right)^{\prime}$ can be written as: $(\alpha, \gamma)^{\prime}+\nu_{i}$, where $(\alpha, \gamma)$ are mean valuations and $\nu_{i} \sim N(0, \Sigma)$ is randomly drawn vector from normal distribution with $\Sigma$ being a diagonal matrix, elements of which represent standard 
deviations around the mean valuations. In our empirical analysis there are no observable individual characteristics which influence the valuation of tariff attributes because such information is confidential.

An individual $i$ chooses in month $t$ tariff $j$ with the highest utility among all the available alternatives, i.e., if $U_{i j t}=\max _{n \in C_{i t}} U_{i n t}$, where $C_{i t}$ is individual $i$ 's choice set in month $t$. The expression for the probability that individual $i$ makes a sequence of tariff choices and estimation strategy are shown in Grzybowski and Liang (2015). The algorithm for estimating a mixed logit model is explained in detail in Train (2003) . ${ }^{12}$ After the estimation, we conduct counterfactual simulations and compute changes in consumer surplus after removal of switching costs and resulting from changes in speed of DSL connections (see Small and Rosen (1981) for the consumer surplus formula).

\section{Estimation Results}

The estimation results for mixed logit model are shown in Table 5. We estimate three model specifications: (i) without speed of connections but with DSL and FttH dummy variables; (ii) with speed of connections in logarithm and (iii) with a set of dummy variables for the speed of connections. The speed of DSL connection depends on copper line loss and is the same for all DSL tariffs in the choice set of an individual consumer. It varies across consumers with the range of possible values is $1,2,5,7$ and $8 \mathrm{MB} / \mathrm{s}$, for which dummy variables are constructed. The speed of FttH connection is assumed to be $100 \mathrm{MB} / \mathrm{s}$ for all consumers. The estimation results are insensitive with respect to the assumption on the speed of $\mathrm{FttH}$ connection of $100 \mathrm{MB} / \mathrm{s}$, which we tested using alternative speed values of 50 and $200 \mathrm{MB} / \mathrm{s}^{13}$ We cannot estimate a model which includes both the connection speeds and technology dummy variables because of collinearity. The first estimation is conducted for a sample of 94,388 consumers and the other two for a sample of 58,455 consumers due to missing data on the speed of DSL connections for

\footnotetext{
${ }^{12}$ We estimate the mixed logit model using Stata procedure mixlogit with 50 Halton draws. See Hole (2007) for estimation details.

${ }^{13}$ The log-likelihood value is also lower for models with FttH speed of $50 \mathrm{MB} / \mathrm{s}$ and 200MB/s than with 100 $\mathrm{MB} / \mathrm{s}$.
} 
the remaining consumers.

In the first estimation without connection speed, consumers have a positive valuation of DSL and FttH connections relative to the choice of the outside option. The valuation is higher for $\mathrm{FttH}$, which is due to higher connection speed. But the valuation of FttH connection may be also influenced by marketing activities and other factors. Moreover, the valuation depends on whether consumers live in areas in which cable broadband is available. The availability of cable broadband reduces the valuation of both DSL and FttH. This may be due to a higher valuation of the outside option in these geographic areas. Consumers who live in these areas and opt to leave our operator can get better deals in terms of connection speed and other services. In the second estimation, with the log of speed and the log of speed interacted with time trend, both variables are highly significant. Consumers have positive valuation of speed which diminishes for higher speed values due to logarithmic specification. Moreover, the value of speed increases over time, which may be due to increasing availability of online services which require high speed connections. In the third estimation, we use a set of speed dummy variables instead of log of speed. In addition, these dummy variables are interacted with time trend. The parameter estimates on all speed dummy variables are very similar, which suggests that consumers have almost the same valuation of DSL connections with speed of 1, 2, 5, 7 and $8 \mathrm{MB} / \mathrm{s}$. Surprisingly, the valuation of speed of $100 \mathrm{MB} / \mathrm{s}$ is not much higher in the first month in the data.

In February 2014, the second month of our data, the valuation of FttH connection with speed of $100 \mathrm{MB} / \mathrm{s}$ was $(8.929+0.551 * 2-9.748) / 9.748=2.9 \%$ higher than the valuation of DSL speed of $8 \mathrm{MB} / \mathrm{s}$ and $6.9 \%$ higher than the valuation of DSL speed of $1 \mathrm{MB} / \mathrm{s}$. In December 2014, the last month of our data, the valuation of FttH connection of $100 \mathrm{MB} / \mathrm{s}$ was $59 \%$ higher than the valuation of DSL speed of $8 \mathrm{MB} / \mathrm{s}$ and $66 \%$ higher than the valuation of DSL speed of $1 \mathrm{MB} / \mathrm{s}$. The interaction term of dummy variable for FttH speed of $100 \mathrm{MB} / \mathrm{s}$ with time trend is significant and positive, while it is insignificant for DSL speed dummy variables. Thus, the valuation of high speed access increases over time, which may reflect growing demand for Internet-based multimedia applications, such as online streaming, data cloud, IPTV and other bandwidth intensive applications. However, besides fast changes over time, the ratio of speed valuations in the last month of the data remains far below the ratio of speed values. Thus, 
consumers have diminishing returns to speed, which may be due to the fact that many key online activities such as emailing, reading news, shopping, browsing and even watching videos does not require speed above $8 \mathrm{MB} / \mathrm{s}$.

The other coefficients are in general significant with anticipated signs. In particular, the price coefficient is significant and negative. The estimate of price coefficient may be biased if consumers who are heavy Internet users tend to choose more expensive FttH tariffs rather than slower and cheaper DSL tariffs. We mitigate this problem by estimating mixed logit model and allowing for consumer-specific unobserved price responsiveness. We observe that consumers differ with respect to price sensitivity since the standard deviation on the price coefficient is significant for the first and third estimations.

The valuation of the contract length is different for triple play and quadruple play tariffs. For triple play tariffs, consumers have a negative valuation of 12 -month contracts but they positively value 24 -month contracts relative to no commitment. The positive valuation may be due to the fact that these contracts are targeted at business and self-employed consumers including tailored features such as dedicated professional portals, significant data storage, fixed IP address and so on. For quadruple play tariffs, consumers have a negative valuation of 12 month contracts relative to no commitment, while the coefficient on 24-month is insignificant. Moreover, consumers have negative valuation of PSTN as a component of triple play offers. Next, quadruple play tariffs with terminal subsidy are less valued on average. In practice, it is more costly to purchase a subsidized handset, for which customers pay each month during the length of their contract, than to purchase a handset without subsidy. Finally, tariffs with unlimited phone calls are more valued as well as tariffs with higher mobile data allowance.

We find that consumers face significant switching costs between tariffs, which increase when the remaining commitment period is longer. Moreover, there are additional switching costs between technologies, from DSL to FttH and the other way around, which in absolute value are much higher than switching costs between tariffs. As we discussed earlier, the additional switching cost may be stemming from the fact that appointment with an engineer is needed to set up the first fiber connection. As shown in Table 3, there are some consumers who switch back to DSL. Based on information from industry experts, this is due to dissatisfaction with FttH 
connection resulting from noisiness of the modem or aesthetic reasons. Switching costs from FttH to DSL tariffs are also much higher than between tariffs based on the same technology. We also find that switching costs to FttH significantly decrease in area in which there is upgraded cable. This may be due to intense marketing campaign in these areas since the operator tries to convince consumers to switch from DSL to FttH technology not to lose them to cable offers of competitors. These marketing campaigns make consumers better informed about the availability and benefits which fiber brings in terms of higher speed. We also observe that consumers have different switching costs since the standard deviation on the coefficient of switching costs is significant for all three estimations.

\subsection{Counterfactual Simulations}

There is an ongoing debate on how to incentivize development of fiber networks, in which one of the key issues is the substitution between DSL and FttH technologies. We use the model to conduct a series of counterfactual simulations to contribute to this debate. In particular, we analyze the role of connection speed, price and switching costs in the transition from DSL to FttH technology. Price and speed differentiate the commercial offer of both technologies, so we should understand how much premium are consumers willing to pay for high speed FttH connection. A related question is whether DSL operators should upgrade connections to VDSL or ADSL+ technologies with speed between 8 and $50 \mathrm{MB} / \mathrm{s}$ in areas in which FttH will not be deployed anytime soon. The opinions on this issue are mixed. The argument against is that VDSL may delay deployment of fiber network. The argument in support is that higher VDSL speed has an immediate positive effect on welfare and increases consumer awareness of speed, which may stimulate further migration to high speed FttH technology. Moreover, for rapid transition process, the price difference should also take into consideration the magnitude of switching costs between tariffs and technologies. We found that there are substantial switching costs which may hold consumers back from changing tariffs, operators and from adopting FttH technology. Thus, to assess the role of speed and price for technology transition without the interference of switching costs, we need to simulate outcomes in the absence of switching costs.

We conduct the following counterfactual simulations. First, we assess the role of switching 
costs. The shares of FttH are predicted by setting different switching costs to zero and holding prices and speeds unchanged. Second, we analyze the role of connection speed in the presence and absence of switching costs. For these two cases, we predict shares of FttH for different values of speed of DSL connections in the range between $1 \mathrm{MB} / \mathrm{s}$ and $8 \mathrm{MB} / \mathrm{s}$. We also make predictions of FttH shares for speed of DSL connections of $50 \mathrm{MB} / \mathrm{s}$, which is achievable by VDSL technology. ${ }^{14}$ Third, we analyze the role of price difference between DSL and FttH tariffs for technology transition.

In the first counterfactual shown in Table 6, we assume that there are no additional switching costs to FttH technology by setting their coefficient to zero. In the second counterfactual, we assume that there are no switching costs between tariffs but there are additional switching costs to FttH and DSL technologies. In the third counterfactual, we assume that there are no switching costs at all. In the current base case in December 2014, the share of FttH in the sample of consumers is $29 \%$. The penetration of $\mathrm{FttH}$ would increase to $54 \%$ in the first counterfactual, would stay at $29 \%$ in the second counterfactual and would increase to $91 \%$ in the third counterfactual. The average consumer surplus would increase by 14.9 Euros in the first case, 8.45 Euros in the second case and 44.4 Euros in the third case. Based on these estimates we can conclude that switching costs between technologies have the greatest impact and slow down the transition process from DSL to FttH. Switching costs between tariffs, which may be due to transaction costs, uncertainty and lack of information also play a role but in combination with switching costs between technologies.

Next, we simulate the shares of FttH connections when speed of all DSL connections is downgraded or upgraded in the presence of switching costs. The possible DSL speed values are 1, 2, 5, 7, $8 \mathrm{MB} / \mathrm{s}$. Table 4 shows that most DSL consumers have access to speed of $5 \mathrm{MB} / \mathrm{s}$ and above. As shown in Table 6, compared to the base case in December 2014, the share of FttH connections would not change at all for speed of all DSL connections ranging between 1 and $8 \mathrm{MB} / \mathrm{s}$. Even if speed of all DSL connections would increase to $50 \mathrm{MB} / \mathrm{s}$, which can be achieved by VDSL technology, the share of FttH connections would remain unchanged. As

\footnotetext{
${ }^{14}$ This counterfactual scenario is not very realistic because VDSL technology is only available to consumers living very close to the exchange.
} 
shown in Table 7, degrading DSL speed to $1 \mathrm{MB} / \mathrm{s}$ would cause an average loss in consumer surplus of 4.4 Euros and upgrading speed to $8 \mathrm{MB} / \mathrm{s}$ would result in an average gain in consumer surplus of 1.75 Euros. Furthermore, upgrading DSL speed to $50 \mathrm{MB} / \mathrm{s}$ would result in an average gain in consumer surplus of 21.1 Euros. On this basis, we can conclude that changing speed of DSL connections in the presence of switching costs will have no effect on the adoption of FttH technology but offering consumers higher speed will increase their welfare.

High switching costs may explain why there is no effect of DSL speed on FttH adoption. We repeat the counterfactual simulations but set all switching costs to zero before changing speed of all DSL connections. The share of FttH connections is not influenced by DSL speed in the range between 1 and $8 \mathrm{MB} / \mathrm{s}$, as compared to the case without switching costs. Only when the speed of all DSL connections increases to $50 \mathrm{MB} / \mathrm{s}$, the share of $\mathrm{FttH}$ connections is lower by 14 percentage points than in the benchmark case without switching costs. Thus, the speed of DSL slows down diffusion of FttH only for speed which is achievable by VDSL technology. At the same time, the average consumer surplus in the absence of switching costs with DSL speed of 1 $\mathrm{MB} / \mathrm{s}$ is smaller by about $(44.4-43.4)=1.0$ Euros than the average consumer surplus in the benchmark case without switching costs, while for DSL speed of $8 \mathrm{MB} / \mathrm{s}$ there is a gain of (44.9 - 44.4) $=0.5$ Euros. Finally, for DSL speed of $50 \mathrm{MB} / \mathrm{s}$ we get an average gain in consumer surplus of $(53.4-44.4)=9.0$ Euros.

Finally, we analyze how price difference between DSL and FttH tariffs, which is about 5 Euros, influences the share of FttH connections. We find that if prices of FttH tariffs were 5 Euros lower, the share of FttH connections would remain unchanged in the presence of switching costs. In the absence of technology switching costs, the share of FttH connections would increase by 30 percentage points to $59 \%$, and in the absence of all switching costs, it would increase by 64 percentage points to $93 \%$. Thus, matching prices of FttH and DSL increases the share of FttH connections only by 5 percentage points relative to the benchmark in the absence of technology switching costs and only by 2 percentage points in the absence of all switching costs.

Overall, our counterfactual simulations illustrate that the values of DSL speed in the range between 1 and $8 \mathrm{MB} / \mathrm{s}$ has almost no impact on consumers decisions to adopt FttH technology. Only an increase in DSL speed to $50 \mathrm{MB} / \mathrm{s}$, which can be available to some consumers via VDSL 
technology, would decrease the share of FttH connections by 14 percentage points but in the absence of switching costs. At the same time, there is a large gain in consumer surplus from increasing DSL speeds. We find that there are significant switching costs between tariffs but the key factor which slows down transition from DSL to FttH are additional switching costs between technologies. In the absence of additional switching costs to FttH technology, the share of FttH connections would increase by about 25 percentage points, while eliminating only switching costs between tariffs would not increase FttH adoption at all. In the absence of all switching costs, FttH share would increase from $29 \%$ to $91 \%$.

\section{Conclusions}

The roll-out of high-speed Internet is one of the flagship initiatives of Europe 2020 strategy proposed by the European Commission in 2010 with the objective to reap the benefits of a digital single market for households and firms. In particular, according to the Digital Agenda for Europe, by 2020, all EU households should benefit of at least $30 \mathrm{MB} / \mathrm{s}$ connection and at least $50 \%$ of EU households should have adopted $100 \mathrm{MB} / \mathrm{s}$ connection or more. Moreover, in September 2016, the Commission announced that by 2025 all European households should have access to connections with speed of at least $100 \mathrm{MB} / \mathrm{s}$. Such speeds of data transmission are not feasible using DSL technology which relies on copper networks belonging to former monopolists, while as of 2014, DSL was used by $59 \%$ EU households connected to Internet.

In this paper, we focus on demand factors which may postpone the adoption of high speed broadband, which are consumer switching costs between tariffs and technologies and low valuation of high connection speed. We analyze the impact of these factors on FttH adoption by estimating mixed logit model based on monthly data on tariff choices made by customers of a single European telecommunications operators between January and December 2014. Our analysis shows there are significant switching costs between tariffs and technologies. In particular, switching costs from DSL to FttH technology slow down the transition process. These costs may be due to the time and effort needed to set up the first fiber connection. In particular, a consumer needs to make appointment with an engineer who must visit the premises to set up 
a connection. Switching costs between tariffs which may be due to transaction costs, uncertainty and lack of information also play a role but in combination with switching costs between technologies. Thus, even if firms deploy fiber networks, the take up of FttH connections by consumers may be slow.

Furthermore, we find that the valuation of DSL speed in the range of 1 to $8 \mathrm{MB} / \mathrm{s}$ is very similar, which may be explained by the fact that basic Internet needs of consumers such as emailing, reading news, shopping, browsing and even watching videos online can be satisfied with connection speeds below $8 \mathrm{MB} / \mathrm{s}$. Surprisingly, the valuation of FttH speed of $100 \mathrm{MB} / \mathrm{s}$ is not much different than the valuation of DSL speed of $8 \mathrm{MB} / \mathrm{s}$ but increases over time. In February 2014, the second month of our data, the valuation of $\mathrm{FttH}$ speed of $100 \mathrm{MB} / \mathrm{s}$ was $2.9 \%$ higher than the valuation of DSL speed of $8 \mathrm{MB} / \mathrm{s}$ and $6.9 \%$ higher than the valuation of DSL speed of $1 \mathrm{MB} / \mathrm{s}$. In December 2014, the last month of our data, the valuation of FttH connection with speed of $100 \mathrm{MB} / \mathrm{s}$ was $59 \%$ higher than the valuation of DSL speed of $8 \mathrm{MB} / \mathrm{s}$ and $66 \%$ higher than the valuation of DSL speed of $1 \mathrm{MB} / \mathrm{s}$. The increasing valuation over time may reflect growing need for high speed connections due to availability of new online services. But besides fast changes over time, the ratio of speed valuations in the last month of the data remains far below the ratio of speed values.

Our findings show that to achieve the objectives of the Digital Agenda for Europe, there is need to reduce consumer switching costs between technologies and tariffs and to convince consumers that they need speed of $100 \mathrm{MB} / \mathrm{s}$ or above. If there is a lack of interest on the side of consumers to give up their slower DSL connections and make a move to faster FttH technology, also firms will have lower incentives to invest in the deployment of FttH. 


\section{Bibliography}

Baranes, E., 2014. "The interplay between network investment and content quality: Implications to net neutrality on the Internet" Information Economics and Policy, 28, pp.57-69.

Bouckaert, J., van Dijk, T. and F. Verboven, 2010. "Access Regulation, Competition, and Broadband Penetration: An International Study" Telecommunication Policy, 34, pp.661671.

Briglauer, W., 2014. "The Impact of Regulation and Competition on the Adoption of FiberBased Broadband Services: Recent Evidence from the European Member States," Journal of Regulatory Economics, 46, pp.51-79.

Cardona M., Schwarz A., Yurtoglu, B.B. and Ch. Zulehner, 2009. "Demand Estimation and Market Definition for Broadband Internet Services," Journal of Regulatory Economics, 35(), pp.70-95.

Dauvin, M. and L. Grzybowski, 2014. "Estimating broadband diffusion in the EU using NUTS 1 regional data," Telecommunications Policy, 38(1), pp.96-104.

Distaso, W., Lupi, P. and F.M. Manenti, 2006. "Platform Competition and Broadband Uptake: Theory and Empirical Evidence from the European Union," Information Economics and Policy, 18, pp. 87-106.

Grzybowski, L. and J. Liang, 2015. "Estimating demand for fixed-mobile bundles and switching costs between tariffs," Information Economics and Policy, 33, pp.1-10.

Grzybowski, L., Nitsche, R., Verboven, F. and L. Wiethaus, 2014. "Market Definition for Broadband internet in Slovakia - Are Fixed and Mobile Technologies in the Same Market?

"Information Economics and Policy, 28, pp.39-56

Heckman, J., 1981. "Statistical Models for Discrete Panel Data," C.F. Manski and D. McFadden, eds. Structural Analysis of Discrete Data with Econometric Applications, Cambridge, MA: The MIT Press, pp.179-195. 
Hole, A.R., 2007. "Fitting Mixed Logit Models by Using Maximum Simulated Likelihood," Stata Journal, 7(3), pp.388-401.

Ida, T. and T. Kuroda, 2006. "Discrete Choice Analysis of Demand for Broadband in Japan," Journal of Regulatory Economics, 29(1), pp.5-22.

Ida, T. and K. Sakahira, 2008. "Broadband migration and lock-in effects: Mixed logit model analysis of Japan's high-speed Internet access services," Telecommunications Policy 32(910), pp.615-625.

LaRose, R., Bauer, J.M., DeMaagd, K., Chew, H.-E., Ma, W., and Y. Jung. 2014. "Public Broadband Investment Priorities in the United States: An Analysis of the Broadband Technology Opportunities Program," Government Information Quarterly, 31, pp.53-64.

Rosston, G., Savage, S.J., and D.M. Waldman, 2010. "Household Demand for Broadband Internet Service," Federal Communications Commission.

Small, K.A. and H.S. Rosen, 1981. "Applied Welfare Economics with Discrete Choice Models," Econometrica, 49, pp.105-30.

Srinuan, P., Srinuan, C. and E., Bohlin, 2012 , Fixed and Mobile Broadband Substitution in Sweden," Telecommunications Policy, 36, pp. 237-251.

Train, K., 2003. "Discrete Choice Methods with Simulation," Cambridge University Press, Cambridge.

Wallsten, S. and S. Hausladen, 2009. "Net Neutrality, Unbundling, and Their Effects on International Investment in Next-Generation Networks," Review of Network Economics, 8, Art. 6 . 


\section{Appendix}

Table 1: Descriptive statistics: old and new tariffs

\begin{tabular}{|l|r|r|r|r|r|}
\hline \hline \multicolumn{5}{|c|}{ Old tariffs } \\
\hline \hline Variable & Mean & Std. Dev. & Min. & Max. & $\mathrm{N}$ \\
\hline Monthly fee (Euros/m) & 62.16 & 25.67 & 21 & 141 & 122 \\
Triple DSL & 0.39 & 0.49 & 0 & 1 & 122 \\
Triple FttH & 0.07 & 0.26 & 0 & 1 & 122 \\
Quadruple DSL & 0.34 & 0.48 & 0 & 1 & 122 \\
Quadruple FttH & 0.2 & 0.4 & 0 & 1 & 122 \\
Handset subsidy & 0.32 & 0.47 & 0 & 1 & 122 \\
Unlimited voice & 0.23 & 0.42 & 0 & 1 & 122 \\
Mobile data allowance (GB) & 0.66 & 1 & 0 & 6 & 122 \\
PSTN & 0.14 & 0.35 & 0 & 1 & 122 \\
Web only & 0 & 0 & 0 & 0 & 122 \\
\hline \hline & New tariffs & \multicolumn{5}{|c|}{} \\
\hline \hline Variable & Mean & Std. Dev. & Min. & Max. & N \\
\hline Monthly fee (Euros/m) & 62.96 & 26.53 & 10 & 147 & 228 \\
Triple DSL & 0.33 & 0.47 & 0 & 1 & 228 \\
Triple FttH & 0.05 & 0.21 & 0 & 1 & 228 \\
Quadruple DSL & 0.35 & 0.48 & 0 & 1 & 228 \\
Quadruple FttH & 0.26 & 0.44 & 0 & 1 & 228 \\
Handset subsidy & 0.47 & 0.5 & 0 & 1 & 228 \\
Unlimited voice & 0.43 & 0.5 & 0 & 1 & 228 \\
Mobile data allowance (GB) & 1.62 & 2.53 & 0 & 10 & 228 \\
PSTN & 0.14 & 0.35 & 0 & 1 & 228 \\
Web only & 0.02 & 0.13 & 0 & 1 & 228 \\
\hline \hline
\end{tabular}

Table 2: Number of consumers switching tariffs between January and December 2014

\begin{tabular}{|l|r|r|}
\hline \hline Switches & Consumers & $\%$ \\
\hline \hline 0 & 56,452 & $60 \%$ \\
1 & 30,500 & $32 \%$ \\
2 & 6,242 & $7 \%$ \\
3 & 1,023 & $1 \%$ \\
4 & 149 & $0 \%$ \\
5 & 21 & $0 \%$ \\
6 & 1 & $0 \%$ \\
\hline Total & 94,388 & $100 \%$ \\
\hline \hline
\end{tabular}


Table 3: Number of switches between types of tariffs between January and December 2014

\begin{tabular}{|r||c|c|c|c|c|}
\hline \hline From/To & Triple DSL & Quadruple DSL & Triple FttH & Quadruple FttH & Leaving \\
\hline \hline Triple DSL & 11,508 & 2,173 & 6,873 & 616 & 562 \\
Quadruple DSL & 27 & 8,486 & 21 & 5,195 & 36 \\
Triple FttH & 1,033 & 9 & 2,878 & 2,041 & 213 \\
Quadruple FttH & 12 & 596 & 12 & 5,345 & 6 \\
New consumers & 191 & 79 & 405 & 117 & 0 \\
\hline \hline
\end{tabular}

Table 4: Copper line loss

\begin{tabular}{|c|c|c|}
\hline \hline Copper line loss & Basic DSL speed & Consumers \\
\hline \hline $60 \mathrm{~dB}-75 \mathrm{~dB}$ & $<1 \mathrm{Mb} / \mathrm{s}$ & 1,006 \\
$45 \mathrm{~dB}-60 \mathrm{~dB}$ & $2 \mathrm{Mb} / \mathrm{s}$ & 6,236 \\
$30 \mathrm{~dB}-45 \mathrm{~dB}$ & $5 \mathrm{Mb} / \mathrm{s}$ & 14,164 \\
$15 \mathrm{~dB}-30 \mathrm{~dB}$ & $7 \mathrm{Mb} / \mathrm{s}$ & 23,952 \\
$<15 \mathrm{~dB}$ & $8 \mathrm{Mb} / \mathrm{s}$ & 13,097 \\
\hline & & 58,455 \\
\hline
\end{tabular}


Table 5: Estimation results

\begin{tabular}{|c|c|c|c|c|c|c|c|c|c|}
\hline & \multicolumn{3}{|c|}{ Est. I } & \multicolumn{3}{|c|}{ Est. II } & \multicolumn{3}{|c|}{ Est. III } \\
\hline & Mean & Time & SD & Mean & Time & SD & Mean & Time & SD \\
\hline Price & $\begin{array}{c}-0.070^{* * *} \\
(0.001)\end{array}$ & & $\begin{array}{c}0.025^{* * *} \\
(0.000)\end{array}$ & $\begin{array}{c}-0.014^{* * *} \\
(0.000)\end{array}$ & & $\begin{array}{l}-0.000 \\
(0.000)\end{array}$ & $\begin{array}{c}-0.056^{* * *} \\
(0.001)\end{array}$ & & $\begin{array}{c}-0.020^{* * *} * \\
(0.000)\end{array}$ \\
\hline Contract $12 \mathrm{TP}$ & $\begin{array}{c}-0.384^{* * * *} \\
(0.013)\end{array}$ & & & $\begin{array}{c}0.581^{* * *} \\
(0.013)\end{array}$ & & & $\begin{array}{c}-0.367^{* * *} \\
(0.016)\end{array}$ & & \\
\hline Contract $24 \mathrm{TP}$ & $\begin{array}{c}6.071^{* * *} \\
(0.035)\end{array}$ & & & $\begin{array}{l}4.601^{* * *} \\
(0.028)\end{array}$ & & & $\begin{array}{c}5.131^{* * *} \\
(0.040)\end{array}$ & & \\
\hline Contract $12 \mathrm{QP}$ & $\begin{array}{c}-1.082^{* * *} \\
(0.055)\end{array}$ & & & $\begin{array}{c}-2.576^{* * *} \\
(0.042)\end{array}$ & & & $\begin{array}{c}-2.756^{* * *} \\
(0.048)\end{array}$ & & \\
\hline Contract $24 \mathrm{QP}$ & $\begin{array}{c}-0.140^{* *} \\
(0.065)\end{array}$ & & & $\begin{array}{c}-1.143^{* * *} \\
(0.057)\end{array}$ & & & $\begin{array}{c}-1.666^{* * *} \\
(0.065)\end{array}$ & & \\
\hline Subsidy & $\begin{array}{c}0.210^{* * * *} \\
(0.047)\end{array}$ & & & $\begin{array}{c}-0.726^{* * *} \\
(0.050)\end{array}$ & & & $\begin{array}{l}-0.009 \\
(0.058)\end{array}$ & & \\
\hline Unlimited & $\begin{array}{c}1.480^{* * *} \\
(0.032)\end{array}$ & & & $\begin{array}{c}0.670^{* * *} \\
(0.029)\end{array}$ & & & $\begin{array}{c}0.206^{* * *} \\
(0.028)\end{array}$ & & \\
\hline Data mobile & $\begin{array}{c}0.370^{* * *} \\
(0.006)\end{array}$ & & & $\begin{array}{c}0.074^{* * *} \\
(0.007)\end{array}$ & & & $\begin{array}{c}0.311^{* * *} \\
(0.008)\end{array}$ & & \\
\hline PSTN & $\begin{array}{c}-0.665^{* * * *} \\
(0.015)\end{array}$ & & & $\begin{array}{c}0.970^{* * *} \\
(0.015)\end{array}$ & & & $\begin{array}{c}-0.475^{* * *} \\
(0.017)\end{array}$ & & \\
\hline Switching & $\begin{array}{c}-3.233^{* * *} \\
(0.013)\end{array}$ & & $\begin{array}{c}-1.192^{* * *} \\
(0.015)\end{array}$ & $\begin{array}{c}-3.812^{* * *} \\
(0.016)\end{array}$ & & $\begin{array}{c}-1.177^{* * *} \\
(0.018)\end{array}$ & $\begin{array}{c}-3.423^{* * *} \\
(0.016)\end{array}$ & & $\begin{array}{c}-1.127^{* * *} \\
(0.018)\end{array}$ \\
\hline Switching to DSL & $\begin{array}{c}-3.914^{* * *} \\
(0.232)\end{array}$ & & & $\begin{array}{c}-2.368^{* * *} \\
(0.411)\end{array}$ & & & $\begin{array}{c}-4.609^{* * *} \\
(0.413)\end{array}$ & & \\
\hline Switching to FttH & $\begin{array}{c}-11.595^{* * * *} \\
(0.582)\end{array}$ & & & $\begin{array}{c}-16.747^{* * * *} \\
(1.005)\end{array}$ & & & $\begin{array}{c}-11.641^{* * *} \\
(1.002)\end{array}$ & & \\
\hline Switching to FttH (cable zone) & $\begin{array}{c}-10.659^{* * *} \\
(0.230)\end{array}$ & & & $\begin{array}{c}-14.042^{* * *} \\
(0.272)\end{array}$ & & & $\begin{array}{c}-9.856^{* * *} \\
(0.264)\end{array}$ & & \\
\hline Switching commitment & $\begin{array}{c}-0.131^{* * *} \\
(0.001)\end{array}$ & & & $\begin{array}{c}-0.108^{* * *} \\
(0.001)\end{array}$ & & & $\begin{array}{c}-0.125^{* * *} \\
(0.001)\end{array}$ & & \\
\hline Leaving commitment & $\begin{array}{c}-0.079^{* * *} \\
(0.007)\end{array}$ & & & $\begin{array}{c}0.192^{* * *} \\
(0.012)\end{array}$ & & & $\begin{array}{c}-0.073^{* * *} \\
(0.009)\end{array}$ & & \\
\hline DSL TP & $\begin{array}{c}10.297 * * * \\
(0.096)\end{array}$ & & & & & & & & \\
\hline DSL TP (cable zone) & $\begin{array}{c}10.300^{* * *} * \\
(0.093)\end{array}$ & & & & & & & & \\
\hline DSL QP & $\begin{array}{c}7.637^{* * *} \\
(0.105)\end{array}$ & & & & & & & & \\
\hline DSL QP (cable zone) & $\begin{array}{c}7.407^{* * *} \\
(0.101)\end{array}$ & & & & & & & & \\
\hline FttH TP & $\begin{array}{c}10.644^{* * *} \\
(0.108)\end{array}$ & & & & & & & & \\
\hline FttH TP (cable zone) & $\begin{array}{c}10.642^{* * * *} \\
(0.099)\end{array}$ & & & & & & & & \\
\hline FttH QP & $\begin{array}{c}6.925^{* * *} \\
(0.118)\end{array}$ & & & & & & & & \\
\hline FttH QP (cable zone) & $\begin{array}{c}7.079^{* * *} \\
(0.109)\end{array}$ & & & & & & & & \\
\hline DSL TP+QP & & $\begin{array}{l}-0.000 \\
(0.011)\end{array}$ & & & & & & & \\
\hline $\mathrm{FttH} \mathrm{TP}+\mathrm{QP}$ & & $\begin{array}{c}0.517^{* * *} \\
(0.013)\end{array}$ & & & & & & & \\
\hline Log speed & & & & $\begin{array}{c}0.710^{* * *} \\
(0.011)\end{array}$ & $\begin{array}{c}0.252^{* * *} \\
(0.003)\end{array}$ & & & & \\
\hline Speed DSL $1 \mathrm{MB} / \mathrm{s}$ & & & & & & & $\begin{array}{c}9.381 * * * \\
(0.310)\end{array}$ & $\begin{array}{l}-0.015 \\
(0.046)\end{array}$ & \\
\hline Speed DSL $2 \mathrm{MB} / \mathrm{s}$ & & & & & & & $\begin{array}{c}9.686^{* * *} \\
(0.160)\end{array}$ & $\begin{array}{l}-0.013 \\
(0.023)\end{array}$ & \\
\hline Speed DSL $5 \mathrm{MB} / \mathrm{s}$ & & & & & & & $9.578^{* * *}$ & 0.011 & \\
\hline Speed DSL $7 \mathrm{MB} / \mathrm{s}$ & & & & & & & $\begin{array}{c}(0.131) \\
9.580^{* * *}\end{array}$ & $\begin{array}{l}(0.018) \\
0.034^{* *}\end{array}$ & \\
\hline & & & & & & & $(0.121)$ & $(0.016)$ & \\
\hline Speed DSL 8 MB/s & & & & & & & $9.748^{* * *}$ & 0.007 & \\
\hline Speed FttH 100 MB/s & & & & & & & $\begin{array}{c}(0.133) \\
8.929^{* * *} \\
(0.118)\end{array}$ & $\begin{array}{c}(0.018) \\
0.551^{* * *} \\
(0.016)\end{array}$ & \\
\hline Observations & $3,998,727$ & & & $2,483,988$ & & & $2,483,988$ & & \\
\hline
\end{tabular}

Standard errors in parentheses: ${ }_{2 *}^{* *} p<0.01,{ }^{* *} p<0.05,{ }^{*} p<0.1$ 
Table 6: Share of FttH subscriptions

\begin{tabular}{|c|c|c|c|c|c|c|c|c|c|c|c|c|c|}
\hline Month & $\begin{array}{r}(0) \text { Current } \\
\text { situation }\end{array}$ & $\begin{array}{r}\text { (1) No FttH } \\
\text { SC }\end{array}$ & $\begin{array}{r}\text { (2) No tariff } \\
\text { SC }\end{array}$ & $\begin{array}{l}\text { (3) No } \\
\text { SC }\end{array}$ & $\begin{array}{r}\text { (4) } 50 \mathrm{MB} / \mathrm{s} \\
\text { with SC }\end{array}$ & $\begin{array}{r}(5) 50 \mathrm{MB} / \mathrm{s} \\
\text { no SC }\end{array}$ & $\begin{array}{r}(6) 1 \mathrm{MB} / \mathrm{s} \\
\text { with SC }\end{array}$ & $\begin{array}{r}(7) 1 \mathrm{MB} / \mathrm{s} \\
\text { no SC} \\
\end{array}$ & $\begin{array}{r}(8) 8 \mathrm{MB} / \mathrm{s} \\
\text { with SC }\end{array}$ & $\begin{array}{r}(9) 8 \mathrm{MB} / \mathrm{s} \\
\text { no SC }\end{array}$ & $\begin{array}{r}(10)-5 \text { Euro } \\
\text { SC }\end{array}$ & $\begin{array}{r}(11)-5 \text { Euro } \\
\text { no FttH SC }\end{array}$ & $\begin{array}{r}(12)-5 \text { Euro } \\
\text { no SC }\end{array}$ \\
\hline 2 & $21 \%$ & $21 \%$ & $23 \%$ & $23 \%$ & $20 \%$ & $14 \%$ & $21 \%$ & $24 \%$ & $21 \%$ & $22 \%$ & $21 \%$ & $21 \%$ & $24 \%$ \\
\hline 3 & $21 \%$ & $21 \%$ & $20 \%$ & $28 \%$ & $21 \%$ & $17 \%$ & $21 \%$ & $29 \%$ & $21 \%$ & $28 \%$ & $21 \%$ & $21 \%$ & $30 \%$ \\
\hline 4 & $21 \%$ & $22 \%$ & $21 \%$ & $32 \%$ & $21 \%$ & $22 \%$ & $21 \%$ & $33 \%$ & $21 \%$ & $31 \%$ & $21 \%$ & $22 \%$ & $33 \%$ \\
\hline 5 & $22 \%$ & $23 \%$ & $22 \%$ & $38 \%$ & $21 \%$ & $28 \%$ & $21 \%$ & $41 \%$ & $21 \%$ & $37 \%$ & $21 \%$ & $23 \%$ & $41 \%$ \\
\hline 6 & $22 \%$ & $25 \%$ & $23 \%$ & $48 \%$ & $22 \%$ & $31 \%$ & $22 \%$ & $53 \%$ & $22 \%$ & $46 \%$ & $22 \%$ & $26 \%$ & $54 \%$ \\
\hline 7 & $23 \%$ & $28 \%$ & $23 \%$ & $55 \%$ & $23 \%$ & $34 \%$ & $23 \%$ & $59 \%$ & $23 \%$ & $53 \%$ & $23 \%$ & $30 \%$ & $59 \%$ \\
\hline 8 & $24 \%$ & $34 \%$ & $24 \%$ & $72 \%$ & $23 \%$ & $41 \%$ & $24 \%$ & $76 \%$ & $24 \%$ & $70 \%$ & $24 \%$ & $36 \%$ & $77 \%$ \\
\hline 9 & $25 \%$ & $36 \%$ & $25 \%$ & $74 \%$ & $24 \%$ & $46 \%$ & $25 \%$ & $76 \%$ & $25 \%$ & $72 \%$ & $25 \%$ & $37 \%$ & $77 \%$ \\
\hline 10 & $26 \%$ & $38 \%$ & $26 \%$ & $80 \%$ & $26 \%$ & $55 \%$ & $26 \%$ & $82 \%$ & $26 \%$ & $79 \%$ & $26 \%$ & $40 \%$ & $82 \%$ \\
\hline 11 & $27 \%$ & $43 \%$ & $28 \%$ & $86 \%$ & $27 \%$ & $67 \%$ & $28 \%$ & $88 \%$ & $28 \%$ & $85 \%$ & $28 \%$ & $47 \%$ & $88 \%$ \\
\hline 12 & $29 \%$ & $54 \%$ & $29 \%$ & $91 \%$ & $29 \%$ & $77 \%$ & $29 \%$ & $92 \%$ & $29 \%$ & $90 \%$ & $29 \%$ & $59 \%$ & $93 \%$ \\
\hline
\end{tabular}

Share of FttH subscriptions in: (0) current situation; (1) without switching costs to FttH technology; (2) without tariff switching costs; (3) without all switching costs; (4) DSL speed upgraded to 50MB/s; (5) DSL speed upgraded to $50 \mathrm{MB} / \mathrm{s}$ and no switching costs; (6) DSL speed degraded to $1 \mathrm{MB} / \mathrm{s}$; (7) DSL speed degraded to $1 \mathrm{MB} / \mathrm{s}$ and no switching costs; (8) DSL speed upgraded to $8 \mathrm{MB} / \mathrm{s}$; (9) DSL speed upgraded to $8 \mathrm{MB} / \mathrm{s}$ and no switching costs; (10) FttH price lowered by 5 Euros; (11) FttH price lowered by 5 Euros and no switching costs to FttH technology; (12) FttH price lowered by 5 Euros and no switching costs.

Table 7: Changes in average consumer surplus in Euros

\begin{tabular}{|c|c|c|c|c|c|c|c|c|c|c|c|}
\hline Month & $\begin{array}{r}\text { (1) No FttH } \\
\text { SC }\end{array}$ & $\begin{array}{r}\text { (2) No tariff } \\
\text { SC }\end{array}$ & $\begin{array}{l}\text { (3) } \mathrm{No} \\
\mathrm{SC}\end{array}$ & $\begin{array}{l}\text { (4) } 50 \mathrm{MB} / \mathrm{s} \\
\text { with SC }\end{array}$ & $\begin{array}{r}\text { (5) } 50 \mathrm{MB} / \mathrm{s} \\
\text { no SC }\end{array}$ & $\begin{array}{r}\text { (6) } 1 \mathrm{MB} / \mathrm{s} \\
\text { with } \mathrm{SC}\end{array}$ & $\begin{array}{r}\text { (7) } 1 \mathrm{MB} / \mathrm{s} \\
\text { no } \mathrm{SC}\end{array}$ & $\begin{array}{r}\text { (8) } 8 \mathrm{MB} / \mathrm{s} \\
\text { with SC }\end{array}$ & $\begin{array}{r}\text { (9) } 8 \mathrm{MB} / \mathrm{s} \\
\text { no SC }\end{array}$ & $\begin{array}{r}\text { (10) }-5 \text { Euro } \\
\text { no SC }\end{array}$ & $\begin{array}{r}\text { (11) }-5 \text { Euro } \\
\text { with SC }\end{array}$ \\
\hline 2 & 0.00 & -9.86 & -9.86 & -23.58 & -32.71 & 4.76 & -6.85 & -1.93 & -11.41 & -5.00 & -14.86 \\
\hline 3 & -0.73 & -9.15 & -14.34 & -23.56 & -35.27 & 4.87 & -11.71 & -1.96 & -15.70 & -5.00 & -19.34 \\
\hline 4 & -1.13 & -8.41 & -15.71 & -23.42 & -34.96 & 4.85 & -13.35 & -1.95 & -16.94 & -5.00 & -20.71 \\
\hline 5 & -1.73 & -8.64 & -18.53 & -23.28 & -36.05 & 4.81 & -16.45 & -1.94 & -19.63 & -5.00 & -23.53 \\
\hline 6 & -2.31 & -8.59 & -20.32 & -23.07 & -36.73 & 4.77 & -18.39 & -1.92 & -21.33 & -5.00 & -25.32 \\
\hline 7 & -3.48 & -9.00 & -24.46 & -22.85 & -39.01 & 4.73 & -22.79 & -1.90 & -25.33 & -5.00 & -29.46 \\
\hline 8 & -5.18 & -8.61 & -28.40 & -22.64 & -41.42 & 4.69 & -26.93 & -1.88 & -29.18 & -5.00 & -33.40 \\
\hline 9 & -6.26 & -8.87 & -30.85 & -22.35 & -43.05 & 4.62 & -29.49 & -1.86 & -31.57 & -5.00 & -35.85 \\
\hline 10 & -9.03 & -8.71 & -35.95 & -21.92 & -46.54 & 4.54 & -34.78 & -1.82 & -36.55 & -5.00 & -40.95 \\
\hline 11 & -11.09 & -8.62 & -39.03 & -21.55 & -49.04 & 4.46 & -37.93 & -1.79 & -39.60 & -5.00 & -44.03 \\
\hline 12 & -14.90 & -8.45 & -44.37 & -21.10 & -53.43 & 4.37 & -43.40 & -1.75 & -44.87 & -5.00 & -49.37 \\
\hline
\end{tabular}

Change in average consumer surplus relative to current situation: (1) without switching costs to FttH technology; (2) without tariff switching costs; (3) without all switching costs; (4) DSL speed upgraded to $50 \mathrm{MB} / \mathrm{s}$; (5) DSL speed upgraded to $50 \mathrm{MB} / \mathrm{s}$ and no switching costs; (6) DSL speed degraded to 1MB/s; (7)

DSL speed degraded to $1 \mathrm{MB} / \mathrm{s}$ and no switching costs; (8) DSL speed upgraded to 8MB/s; (9) DSL speed upgraded to $8 \mathrm{MB} / \mathrm{s}$ and no switching costs; (10) FttH price lowered by 5 Euros; (11) FttH price lowered by 5 Euros and no switching costs to FttH technology; (12) FttH price lowered by 5 Euros and no switching costs. 